\title{
Visibilizando la Concepción del Tiempo Qom en Instituciones Educativas del Gran Chaco Argentino
}

\section{Making the Qom's Conception of Time Visible in Educational Institutions of Argentina's Great Chaco}

\author{
iD Geraldine Chadwick' \\ iD Leonor Bonan² \\ Dosé Antonio Castorina ${ }^{1}$

\begin{abstract}
'Universidad de Buenos Aires (UBA), Instituto de Investigaciones en Ciencias de la Educación (IICE), Facultad de Filosofia y Letras, Buenos Aires, Argentina. Autora correspondiente: geralchad@ccpems.exactas.uba.ar

${ }^{2}$ Universidad de Buenos Aires (UBA), Instituto de Investigaciones (CeFIEC), Facultad de Ciencias Exactas y Naturales,
\end{abstract} \\ Buenos Aires, Argentina.
}

Resumen: El objetivo general de este proyecto fue indagar sobre las concepciones de tiempo diurno y nocturno que circulan por las aulas multiculturales de diferentes instituciones educativas de la Provincia de Chaco, Argentina. Con este fin, se eligió anclar en la etnia Qom que forma parte de la familia lingüística Guaycurú. A través de una investigación-acción se decidió generar diferentes actividades a implementar en escuelas secundarias a las que asisten estudiantes, mayoritariamente de la etnia Qom. Se obtuvieron registros mediante producciones escritas, observaciones, etc. Finalmente, se analizaron los resultados obtenidos, mediante los cuales se observa una concepción de tiempo cíclica donde cobran vital relevancia la observación de las posiciones aparentes del Sol a lo largo del día, la luminosidad atmosférica durante la noche y el canto de aves específicas para ambos momentos. La realización de las tareas propuestas promovió el acceso a un fenómeno desde los conocimientos ancestrales, ofreciendo una mirada diversa sobre los fenómenos naturales.

Palabras clave: Etnia Qom; Concepto de tiempo; Didáctica de las ciencias naturales; Educación intercultural; Educación escolar indígena.

\begin{abstract}
The general objective of this project was to investigate day and night time conceptions that circulate in multicultural classrooms of different educational institutions of the Province of Chaco, Argentina. To that end, the Qom ethnic group has been chosen, which is part of the Guaycurú family language. Through action research, it was decided that different activities would be generated and implemented in secondary schools attended by students, mostly from the Qom ethnic group. Records were obtained through written annotations, observations, etc. Finally, the obtained results show a cyclic time conception, where the observation of apparent positions of the Sun throughout the day, atmospheric luminosity during the night, and specific bird songs for both moments are of vital relevance. The completion of the proposed tasks promoted access to a phenomenon dating back to ancestral knowledge, offering a diverse view on natural phenomena.

Keywords: Qom ethnic group; Time conception; Natural sciences didactics; Intercultural education; Indigenous school education.
\end{abstract}

Recebido em: 28/03/2020

Aprovado em: 11/05/2020 


\section{Introducción}

Este trabajo consiste en el primer trabajo de campo exploratorio de una investigación doctoral en Ciencias de la Educación que se manifiesta en la combinación interdisciplinar de la Didáctica de las Ciencias Naturales (DCN) y la Educación Intercultural Bilingüe (EIB), de forma tal de promover una enseñanza de las ciencias que abarque las cosmovisiones de los pueblos originarios (BONAN, 2017). Como consecuencia de las diferentes tensiones que permearon los avances de la EIB no ha logrado repercutir relevantemente en la educación de las comunidades originarias de Argentina, quienes están atravesados por la desigualdad social además de la educativa (HIRSCH, 2010). Una causa importante de esta carencia de impacto es la falta de formación docente y la insuficiencia de materiales didácticos interculturales y multilingües (HECHT; SCHMIDT, 2016). A las ya tradicionales dificultades de la enseñanza, se suma la falta de significatividad de los abordajes que no contemplan un otro culturalmente diferente y las escasas investigaciones que vinculan la enseñanza con las culturas vernáculas. Siendo un área de vacancia la Educación Intercultural en lo que respecta a las Ciencias Naturales, el objetivo principal de este trabajo de investigación es indagar sobre las concepciones de tiempo diurno y nocturno en contextos escolares multiculturales. Asimismo, el objetivo final de este conocimiento propone colaborar con la producción de prácticas significativas para las poblaciones originarias, en particular, de la Argentina. Se eligió como temática el tiempo, preguntarse ¿qué es el tiempo? No ha sido patrimonio único de la física o la filosofía según Elías (2010), el tiempo como palabra es símbolo de una relación que un grupo humano establece entre dos o más procesos, de entre los cuales toma uno como cuadro de referencia o medida de los demás. Los marcos de referencia pueden ser procesos naturales tales como el movimiento de las estrellas, el cambio de las estaciones o un continuum físico como puede ser un reloj. Tales unidades de medición deben estar socialmente estandarizadas por los miembros de un grupo social, ya que las especificaciones del tiempo cumplen funciones de integración y coordinación (ELÍAS, 2010). Es decir, que el tiempo es concebido de acuerdo a los grupos sociales en diferentes momentos de su historia. Algo así como una mirada, de Elías, que desnaturaliza el concepto de tiempo, interpretado desde la civilización occidental. Este mismo autor afirma que los seres humanos utilizan secuencias repetibles de duración limitada como medida de secuencias sociales irrepetibles, como indicadores para saber cuándo se deben emprender ciertas actividades y cuánto tiempo deben durar (ELÍAS, 2010). A su vez avala que la determinación y percepción del tiempo es un problema cognitivo porque está relacionado con la capacidad humana de síntesis y que el conocimiento es acumulable y perfectible no sólo por los individuos sino también por los grupos sociales a través de generaciones. La delimitación del tiempo es una relación social ya que nace de una necesidad colectiva y se realiza para organizar y satisfacer quehaceres sociales (ELÍAS, 2010).

A través de una metodología investigación-acción se realizaron diversas acciones anticipadas que condujeron a conocer posibles representaciones del tiempo desde las perspectivas de la ciencia erudita y una perspectiva vernácula particular, la de la etnia Qom. Esta comunidad aborigen desciende de la familia lingüística Guaicurú, actualmente habitan en el territorio del Gran Chaco argentino específicamente en parte de las provincias de Chaco y Formosa ubicadas al norte de la Argentina. Los Qom poseen una tradición cazadorarecolectora es por eso que desde la época precolombina practicaban una economía 
nómade o seminómade basada en la caza, la pesca, el meleo y la recolección (TOLA, 2012). En la actualidad, algunos miembros del pueblo Qom practican la agricultura, trabajan como asalariados y viven en comunidades rurales y urbanas. La expropiación de tierras, la reubicación de la población y la conversión al cristianismo provocaron una transformación y reacomodación de su cultura al igual que las de otros pueblos originarios argentinos. Sin embargo, han mantenido su cosmovisión y su lengua de manera viva y perdurable en el tiempo.

El uso de la lengua Qom se da en ámbitos urbanos y rurales, diversas encuestas realizadas sobre la población Qom-hablante demuestra que el nivel de vitalidad de la lengua depende en su mayor medida de la localización geográfica de sus hablantes en relación con sus edades y actitudes tomadas respecto al uso de la lengua vernácula (CENSABELLA, 2005). Si bien los integrantes de la etnia Qom poseen la propiedad comunitaria del territorio ocupado, ni las parcelas de campo ni las casas pueden venderse en beneficio de sus ocupantes y si son abandonadas deben pasar a manos de otro miembro de la comunidad indígena que las necesite. Por lo general, cada familia, y a veces más de una, ocupa una casa de material con dos o tres ambientes y un territorio.

En el ámbito rural, las tensiones entre la sociedad dominante (policías, maestros, religiosos, etc.) y las comunidades Qom son en su mayor parte conflictivas. Los prejuicios racistas (abiertos o camuflados) se hacen carne en muchos miembros de la sociedad dominante de estas regiones. Por otra parte, es necesario destacar el hecho de que en los ámbitos rurales todavía existen muchos ancianos monolingües Qom que hablan español en contadas ocasiones. En el resto de la población de estas regiones, el uso del español es secundario y aumenta a medida que disminuye la edad de los hablantes. De tal forma que casi todos los niños de estas localidades son bilingües Qom-español, con diversos grados de competencia según los casos, dado que utilizan la lengua materna en el hogar, con familiares y niños Qom de la misma edad en la mayoría de las circunstancias (CENSABELLA, 2005). El español se aprende al entrar a la escuela a la edad de 5 o 6 años y también con otros niños ajenos a su cultura o con parientes Qom provenientes de zonas urbanas que los visitan durante un lapso prolongado. Así, el pasaje por la escuela primaria refuerza el aprendizaje del español, a pesar que muchos niños abandonan la escuela por repitencia.

En lo que respecta a este trabajo de investigación, anticipadamente se examinaron las representaciones de los Qom sobre el tiempo a través de estudios lingüísticos, antropológicos y etnocientíficos con el objetivo de describir los saberes vernáculos de modo de lograr explicar las representaciones particulares de los participantes. Se diseñó una serie de intervenciones en diferentes escuelas secundarias de la Provincia de Chaco para explorar qué representaciones circulaban por sus aulas (BONAN, 2017).

A continuación se describirá el estado de la cuestión a investigar de forma tal de caracterizar el contexto educativo de la investigación. Luego, se describirá la metodología y actividades didácticas empleadas para analizar las particularidades de la concepción de tiempo diurno y nocturno Qom. Finalmente se dará cuenta de las conclusiones obtenidas en este trabajo de indagación. 


\section{Colonialidad, Educación Intercultural y Educación Intercultural Bilingüe}

Dada la diversidad cultural que conforma el territorio de Nuestra América (CULLEN, 2017) y siguiendo a Walsh (2005), la representación de las diferentes conceptualizaciones propias de esta región no son tenidas en cuenta dentro de la actual geopolítica dominante. Las concepciones globalizadas, regidas por el mercado junto a las cosmovisiones neoliberales, establecen un orden único en las esferas sociales, económicas y políticas. Como consecuencia de este fenómeno se establece un orden de conocimiento eurocéntrico privilegiado que organiza el mundo y se caracteriza por seguir siendo colonial. La historia del territorio de Nuestra América está regida geohistóricamente, geopolíticamente y geoculturalmente privilegiando la idea de progreso de la mano de la cultura blanca-europea. De esta forma, se establece una jerarquía de color de piel desnivelando a todos aquellos que posean un color diferente. Para enfrentar este fenómeno la interculturalidad es una pieza clave como proyecto político y epistémico.

La interculturalidad se propone recuperar y colocar en un lugar de valoración los conocimientos ancestrales interrelacionándolos con los saberes occidentales de manera tal de cimentar relaciones simétricas entre ellos. Así, la interculturalidad se orienta a la construcción epistémica de una nueva condición social del saber, concebida como parte de un proyecto político como respuesta a los legados coloniales aun presentes en Nuestra América. Walsh (2005) describe cómo se produce una pérdida crítica y transformadora en el ámbito estatal asumiendo un sentido multi o pluri culturalista, comprendido como la incorporación o inclusión de la diversidad étnica dentro de estructuras políticas, sociales y de conocimiento existentes sin cambiar la presente hegemonía actual dominante.

La educación intercultural solo tendrá impacto, significación y valor si en el acto político-pedagógico es asumida de forma crítica de forma tal de poder transformar a la sociedad (FREIRE, 2004). Se ha ocultado y minimizado la conflictividad de dominación, poder y colonialidad que continúan formando parte de las sociedades e instituciones de Nuestra América. Por lo tanto, es imprescindible caracterizar las relaciones capitalismo colonial/ moderno y el eurocentrismo en torno al concepto de raza y la conquista de América. Siguiendo a Santos (2006) en cualquier sociedad donde hay colonialismo y capitalismo, estos dos son parte integrante de una misma constelación histórica, sin que ninguna tenga privilegio explicativo. Así, se construyeron identidades sociales históricas tales como: los indios, negros y mestizos, a quienes se les adjudicaba el trabajo esclavo, asalariado y subordinado.

De esta manera, la idea de raza otorgaba legitimidad a las relaciones de dominación, explotación y articulación de diferentes formas de control no solo de trabajo, sino también de los recursos y productos en torno del capital, adjudicándoles a los pueblos dominados una posición de inferioridad natural, dados sus rasgos físicos como conductuales así como también sus conocimientos culturales. Gramsci (1975) hace referencia a la hegemonía cultural, mediante la cual la realidad cultural (creencias, valores, explicaciones y percepciones) es dominada por una clase social, estableciéndose, de esta manera los patrones de validez universal.

\footnotetext{
'La concepción de raza es científicamente perimida aunque las reflexiones que surgen de su consideración pueden relacionarse con una discriminación estructural por la diferencia de rasgos y cultura.
} 
Como consecuencia de este fenómeno, se instaura un proceso implícito mediante el cual los dominados se ven obligados a aceptar un modelo cultural ajeno que los oprime desnivelándolos (en todo sentido) de manera evidente por su raza de pertenencia (QUIJANO, 2003). Este hecho, los fuerza a reacomodar las escenas de su vida cotidiana para estar insertos en la estructura social y cultural de los dominantes desde los comienzos de la conquista Estas consecuencias políticos-sociales impactan en la realidad escolar, Freire (1973) describe la invasión cultural como extensión, una actitud contraria al diálogo, el cual es la auténtica base de la educación. La dialogicidad y antidialogicidad son teorías de acción cultural antagónicas, siendo la primera liberadora y la segunda opresora. Esto se debe a que la primera es colaborativa y su praxis se da organizando y uniendo a los intervinientes, fomentando la síntesis cultural. Mientras que la antidialogicidad divide, conquista y manipula produciéndose así la invasión cultural (FREIRE, 1970).

De esta manera, el dominador impone su palabra falsa sobre los oprimidos ya que sin diálogo no es posible llevar adelante una praxis auténtica para ambos. En esta situación, los oprimidos niegan su palabra de forma tal que no admiran legítimamente el mundo porque no pueden cuestionarlo, denunciarlo o transformarlo, sino que se adaptan a la realidad de forma servil al dominador (FREIRE, 1970). Podemos afirmar entonces que el compromiso verdadero incluye la transformación de la realidad en la que se encuentran los oprimidos, siendo protagonistas en dicho proceso y este se da mediante el diálogo verdadero sin engaños o falsedades, no permitiendo que actúen como sujetos.

Tal como afirma Walsh (2010), lo intercultural en la EIB se ha construido mediante dos factores, el primero en términos lingüísticos y el segundo recae en el reconocimiento, respeto y la tolerancia del otro culturalmente diferente sin generar un cambio mayor o transformación. Como consecuencia de estos sucesos la interculturalidad se vuelve funcional al sistema neoliberal porque privilegia el bienestar individual, el sentido de pertenencia de cada individuo a un proyecto moderno de nación y la apropiación de una cultura importada (WALSH, 2010). A pesar de esto se reconoce que la EIB es para todos sin embargo, su propuesta pedagógica recae en el entendimiento de lo intercultural centrado en el indígena. Como consecuencia de este fenómeno, superficialmente se incorporan asignaturas relacionadas a la diversidad cultural y lingüística, dejando de lado la relación de conocimientos y saberes ancestrales dado que no se reconoce que el conocimiento y la ciencia no son únicos y singulares. Es por eso que es necesario identificar saberes ancestrales como conocimientos válidos de gran necesidad e importancia para todos.

\section{Estado de la Cuestión}

Actualmente, existen leyes nacionales e internacionales que avalan y caracterizan el respeto y derecho de los pueblos originarios a ser educados en sus propias lenguas, culturas y cosmovisiones, las cuales se integran en la EIB como una de las ocho modalidades del Sistema Educativo Argentino. Siguiendo a Thisted (2016), una característica histórica de este Sistema Educativo fue el discurso pedagógico normalizador, mediante el cual se procuraba la unificación de la lengua y un modelo étnico esencial e indivisible. Este último rigió el sistema escolar de Argentina durante casi un siglo privilegiando el precepto homogenizante y supresor de la diversidad cultural originaria. Asimismo, embanderaba discursos funcionales y orientaciones escolares a normas y prácticas raciales, modernas sobre otros 
considerados irracionales y premodernos (THISTED, 2016). Asimismo, la escuela fue una pieza fundamental en la definición de un nosotros-otros, siendo los últimos considerados estigmatizables e inferiores fomentando la propagación y naturalización de tales jerarquías.

Si bien la instauración de la EIB como modalidad del Sistema Educativo Argentino es una respuesta a las largas luchas de movimientos sociales indígenas en contra del legado colonial, en la práctica deja inalterados modos de organización de espacios, tiempos, relaciones de poder, contenidos y prácticas propias de la escuela moderna. Por lo tanto, se subordina la integración de estudiantes indígenas a variables hegemónicas (THISTED, 2016). Así, las aulas se permean de cuestiones culturales de forma meramente descriptiva, reduciendo los procesos de producción de saberes ancestrales.

Al interior de las instituciones educativas de la provincia del Chaco, en particular, coexisten de diferentes culturas que conviven en un mismo espacio-tiempo, siendo este un terreno fértil en el que transitan diferentes representaciones sobre un mismo fenómeno (CHADWICK;BONAN, 2018). El currículo escolar de primaria y secundaria de Chaco dispone que en las lenguas se porta la cultura, existiendo espacios áulicos plurilingües y multiculturales donde es necesario reconocer, promocionar y respetar dichas lenguas y culturas. De esta manera se fomenta el resguardo de la identidad y promoción del diálogo colocando a todas las culturas intervinientes en un lugar de valoración cuestionando la hegemonía de la cultura dominante. Por este motivo, se debe comprender una doble racionalidad para las propuestas de trabajo áulicas debido a que los niños de otras culturas poseen una racionalidad vernácula y otra científica (ARGENTINA, 2012).

Como consecuencia de este fenómeno, el sistema educativo chaqueño ha circulado por distintas prácticas pedagógicas y por la formación de docentes pertenecientes a las comunidades originarias asignados a resolver la barrera de comunicación. Los Profesores Interculturales Bilingües poseen las mismas facultades que los docentes tradicionales y entre ambos tienen la obligación de articularse y complementarse como pareja pedagógica. A pesar de esto, en la práctica no son contempladas de esa manera ya que si bien se encuentran dentro del sistema educativo formal, su función no está reglamentada dentro del estatuto docente, por lo que tienen un rol marginal dentro del mismo debido a que no se les reconoce su función pedagógica (HIRSCH; SERRUDO, 2010).

Muchas veces realizan funciones subordinadas al docente tradicional, por lo que no se trata de un trabajo cooperativo entre dicha pareja pedagógica. Su tarea en la vida real oscila entre las funciones administrativas, de maestranza y la de oficiar de puente o mero traductor entre el español y la lengua materna de los niños. En pocas palabras, el profesor indígena ocupa lugares bastantes dispares e inciertos según la lógica de las instituciones que los incorporan. La escuela es un territorio de tensiones culturales donde se permean diferentes factores y actores sociales tales como: exclusión y pobreza por una parte, estudiantes y docentes de diferentes orígenes por otra (CHADWICK; BONAN, 2018). Todas las cuestiones anteriormente mencionadas dan cuenta de que en general no existe enseñanza intercultural.

\section{Educación Intercultural Bilingüe en el Contexto de Nuestra Investigación}

Uno de los obstáculos más importantes que enfrenta la formación de formadores en EIB es la falta de propuestas de enseñanza que realicen integraciones culturales alrededor de un mismo hecho o fenómeno. La EIB propone un encuentro entre culturas para generar prácticas educativas significativas para las poblaciones para las que se destinan. Es por 
eso clave en este trabajo de investigación apelar a marcos teóricos de la DCN que no ha consolidado una línea específica de interculturalidad. En este aspecto, cuando el objeto de estudio no se incluye en una línea de investigación existente es necesario definirlo a través de varias de sus fuentes teóricas (BONAN, 2005). En lo que respecta a nuestro problema de investigación se acudió a la etnoastronomía, la lingüística y la antropología debido a contribuyen de manera preciada en la caracterización de algunos aspectos de la enseñanza de las Ciencias Naturales en contextos de EIB. Tal como afirma Bonan (2005), todos estos elementos adquieren una especial dimensión cuando se refrendan en las prácticas educativas que se desarrollan en las aulas que presentan diversidad lingüística y cultural. Así la enseñanza de las Ciencias Naturales en contextos de interculturalidad debe ser entendida como una educación abierta, flexible, basada en el diálogo intercultural, donde cada cual desde su cultura establece diálogos con las otras presentes (ZIRADICH, 2010).

La Didáctica de las Ciencias Naturales (DCN) ha desarrollado una amplia línea de investigación en las llamadas Ideas Previas (DRIVER; GUESNE; TIBERGHIEN, 1989), Concepciones alternativas (CUBERO, 1994) e Imagen de Ciencia y Científico (ADÚRIZ-BRAVO et al., 2006), las cuales describen que los estudiantes no llegan con la mente en blanco a las aulas sino que traen sus propias ideas. Asimismo, mediante estas ideas los estudiantes interpretan y explican los fenómenos naturales que son enseñados durante las clases de Ciencias Naturales.

En casos reducidos estas ideas que traen los estudiantes se asemejan con los conocimientos científicos escolares enseñados durante las clases de Ciencias Naturales ya que por lo general existen discordancias entre sus creencias y las ideas científicamente aceptadas. A lo largo del desarrollo de la línea de las ideas previas, concepciones alternativas o imágenes de ciencia y científico se han publicado diferentes clasificaciones sobre las ideas de los estudiantes en distintas áreas del conocimiento pero en la mayoría de los casos pertenecientes a la cultura occidental sin dar cuenta de las culturas de etnias o identidades diferentes.

A la hora de ahondar en la Educación Intercultural, es necesario establecer algunos paralelismos entre las ideas previas, concepciones alternativas o imágenes de ciencia y científico y las cosmovisiones indígenas. Estas últimas tienden a ser fenómenos sociales, ya que son testeadas por el propio sujeto en el mundo y con las personas que lo rodean. A partir de la niñez, cada persona interactúa con su entorno físico y social y es a través de esta miríada de interacciones con el entorno que las presuposiciones de la visión de mundo son inconscientemente construidas o apropiadas en un proceso, porque si bien tienen una lado indiscutiblemente construido, la construcción de ideas se hace como reconstrucción de la cosmovisión social preexistente. El proceso ocurre durante un largo período de tiempo, siendo los años formativos de la infancia de la mayor importancia. A través de los años de escolarización, la educación formal contribuye al desarrollo de una polifasia de una cosmovisión en la que se asienta la ciencia occidental y otra en la que radican los saberes vernáculos. Esta polifasia provee las bases sobre las cuales los esquemas cognitivos son construidos durante el proceso de aprendizaje.

Como el objetivo principal de este trabajo es indagar sobre las concepciones de tiempo que circulan por las aulas de diversidad cultural se debe recordar que ciertos fenómenos naturales tales como: el movimiento aparente de los astros, el desarrollo de las especies vegetales o la sucesión de las generaciones, plantean preguntas que requieren respuestas culturales. Al nivel más elemental de sociabilidad, hablar del tiempo es una convención 
social (CARBONELL CAMÓS, 2004). Este mismo autor afirma que la vivencia del tiempo es una experiencia subjetiva en la cual existe un fuerte contraste entre el tiempo medido de forma mecánica por los relojes y el tiempo vivido o experimentado a nivel humano, incluso en relación a su cómputo. Por lo tanto, podemos decir que el tiempo es una construcción social y que culturas diferentes conceptualizan el tiempo de manera distinta con lo cual hoy se tiende a considerar el tiempo como una práctica social configuradora de la identidad (CARBONELL CAMÓS, 2004).

De esta afirmación se deriva que la noción de tiempo no es la de una cantidad pura, homogénea en todas partes, siempre comparable a ella misma y mensurable, sino que en la concepción de tiempo caben otras consideraciones que simplemente las de mayor, menor e igual: caben consideraciones de aptitud, oportunidad, continuidad, constancia, similitud y equivalencia. Desde esta perspectiva, las unidades de tiempo no son unidades de medida en sentido absoluto, sino de ritmo. Si bien la observación de ciertos fenómenos naturales y astronómicos provee elementos para ayudar a fijar el paso del tiempo, estos fenómenos, a los que podríamos denominar índices fenomenológicos, son irregulares como mínimo fluctuantes. Por lo tanto, debemos reconocer un esfuerzo cultural previo que consiste en la selección de determinados índices fenomenológicos y el rechazo de otros, así como su interpretación en términos de signos numéricos convencionales.

Asimismo, la representación del tiempo en el calendario es esencialmente rítmica. Sin embargo, el ritmo del tiempo no tiene necesariamente por modelo la periodicidad natural constatada por la experiencia, sino que las sociedades tienen en ellas mismas la necesidad y los medios para instituir dicho ritmo (CARBONELL CAMÓS, 2004). Este mismo autor afirma que el calendario no tiene por objeto mesurar el paso del tiempo, considerado como una cantidad, sino que proviene de una concepción cualitativa del tiempo y de los momentos discontinuos heterogéneos y giratorios que lo componen. Leach (1971) afirma que se habla de medir el tiempo como si el tiempo fuera un objeto concreto que esperara ser medido cuando en realidad creamos el tiempo al crear intervalos en la vida social ya que antes de esto no hay tiempo que pueda ser medido.

Para abordar la problemática planteada en el trabajo de investigación propuesto anclamos en la etnia Qom por lo que fue necesario profundizar en su cosmovisión a través de fuentes antropológicas (TOLA, 2012). Su cultura es de transmisión oral y asume el universo como un todo. Según trabajos antropológicos los Qom describen al tiempo como un espiral donde los antepasados conviven con los seres del presente (TOLA, 2016). Por otra parte, un autor Qom (SÁNCHEZ, 2010) afirma que el Sol es un indicador diurno del paso del tiempo porque establece los intervalos de luz disponibles para las tareas de caza, el meleo y la recolección. Con toda esta información diseñamos, elaboramos e implementamos un taller de 2 horas destinado a estudiantes de escuelas secundarias.

\section{Aspectos Metodológicos}

Para esta primera etapa de indagación doctoral se diseñaron una serie de actividades didácticas exploratorias. Su fin fue realizar un rastreo a primera instancia acerca de las representaciones vernáculas sobre el tiempo que circulaban en instituciones educativas del Gran Chaco. La indagación se realizó mediante una metodología de investigaciónacción (SIRVENT; RIGAL, 2012), se planificaron pasos y estrategias a realizar para llevar a cabo la acción y evaluar sus resultados. Así comprender la formulación y evaluación 
del problema planteado en la situación educativa. Dicho problema puede hacer referencia a la necesidad de innovar o modificar estrategias de enseñanza. Se elaboraron registros a través de análisis de documentos, observaciones y registros de audio.

Esta metodología de investigación orienta la realización de acciones con fines específicos en contextos poco característicos para el investigador respondiendo a los problemas, expectativas y necesidades que tengan planteados las instituciones, en general y sus miembros, en particular. De esta forma, las acciones intentan modificar la realidad una vez comprendida la problemática estudiada convirtiéndose en una forma de investigación autorreflexiva de los actores implicados, con el fin de mejorar y comprender sus prácticas sociales educativas como así también las situaciones en las que estas se realizan.

En particular, se abordaron instituciones escolares de contextos rurales (Figura 1), se relevaron las representaciones de diversos actores sobre el tiempo desde una perspectiva multicultural, se realizaron registros y evaluaciones sobre todas la acciones en relación a los objetivos diseñados.

Figura 1 - Instituciones escolares de contextos rurales de la Provincia de Chaco, Argentina

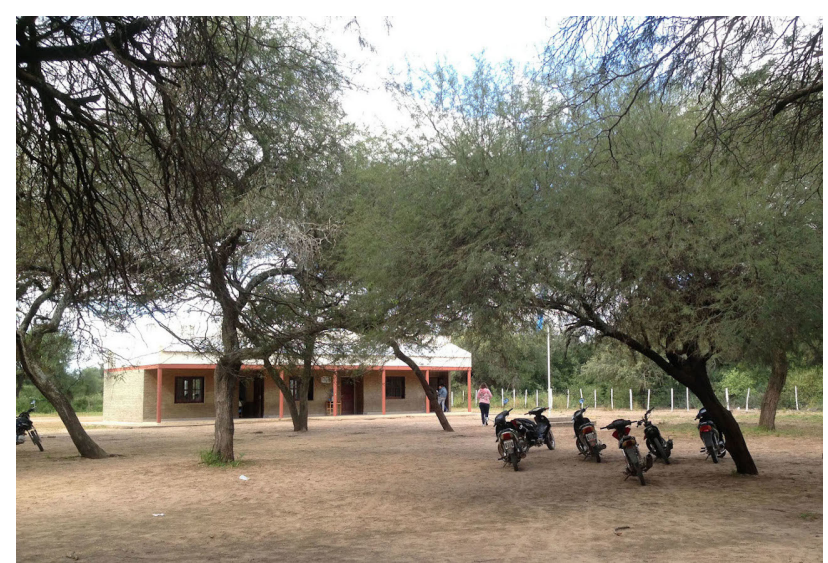

Fuente: fotografía tomada durante la investigación.

Teniendo en cuenta que el objetivo general de este trabajo de investigación es indagar sobre la concepción de tiempo Qom con el fin último de aportar a la creación de materiales didácticos en contextos de diversidad cultural.

La intervención se realizó en tres encuentros de 2 horas y fue llevada a cabo en la Escuela de Enseñanza Media, n. 168 y sus dos anexos. Los destinatarios fueron aproximadamente 50 estudiantes de instituciones secundarias que trabajaron en grupos de 3 a 5 estudiantes. Buscamos que las actividades apuntaran a conocimientos ancestrales específicos sobre el tiempo por lo que se basaron en un reloj de la cultura Qom compuesto por diferentes períodos temporales, cuyas denominaciones están dadas en lengua vernácula y se basan en la observación precisa de las posiciones solares a lo largo de un día, la luminosidad atmosférica durante la noche. La propuesta didáctica buscó que los participantes generaran hipótesis y que la comunicación no se basara únicamente en el lenguaje oral, ya que debieron armar un collage de imágenes y dibujos relacionados con el reloj Qom. Por otra parte, la significatividad de las actividades propuestas se puso de manifiesto a través de la participación activa de los estudiantes que, incluso, sostuvieron discusiones acaloradas para alcanzar acuerdos (Figura 2). 
Figura 2 - Grupos de estudiantes trabajando en las consignas planteadas

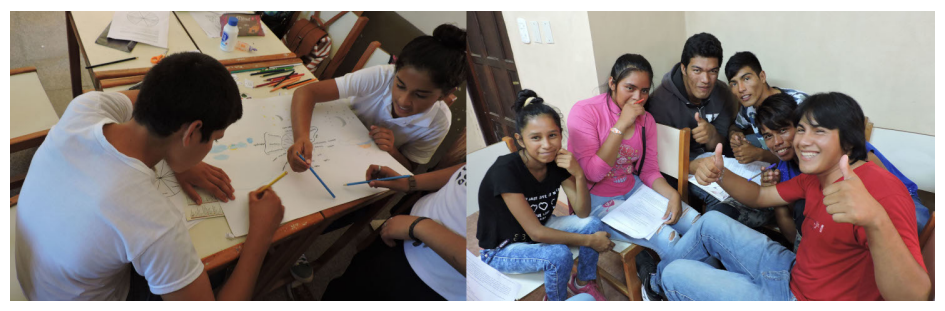

Fuente: fotografías tomadas durante la investigación².

La realización de las tareas pautadas promovió el acceso a un fenómeno desde los conocimientos ancestrales, ofreciendo una mirada diversa sobre los fenómenos naturales, promoviendo la puesta en escena de temáticas comúnmente silenciadas al interior de las aulas escolares. A continuación se presentan brevemente las actividades planificadas:

Actividad 1: Presentación de los participantes.

- Se presentan los estudiantes de la escuela, luego los docentes intervinientes y se explica de forma oral los objetivos formativos de las actividades a realizar.

Actividad 2: Disparador: La concepción de tiempo maya.

- Lee el siguiente texto sobre la concepción del tiempo maya y luego responde la consigna planteada: Los mayas estaban preocupadísimos por la vida del hombre y el paso del tiempo es por eso que estudiaban el movimiento de los astros y de los ciclos naturales para mejorar la calidad de vida. Como consecuencia de esto, obtuvieron beneficios de la agricultura, de las actividades diarias, etc. Los miembros de la comunidad maya se dedicaron a conocer el ritmo de los astros, en particular el del Sol porque en su cultura era la clave de toda la temporalidad. La creencia de los mayas se basaba en que los acontecimientos tanto naturales como humanos se repetían con lo cual podemos decir que tuvieron una concepción cíclica del tiempo. Esto se debe a que observaban con mucho esmero y cuidado los ciclos naturales, los cambios estacionales, etc. Como el movimiento del Sol también es cíclico, sale todos los días por el este y se esconde por el oeste, probablemente pensaron que toda la temporalidad también lo era. Para saber cuándo debían sembrar, cuándo se iba a dar un fenómeno meteorológico importante tenían que saber qué había pasado en el ciclo anterior y para eso crearon un sistema de calendarios mediante los cuales medían las apariciones de los astros en el horizonte.

- La idea de tiempo maya es muy diferente a la del tiempo occidental. Esta última es una línea recta donde hay un pasado y un futuro mientras que la idea del tiempo maya nos habla de posibilidad infinita del tiempo ya que todo se repite. Esto se debe a que el presente era vivido en una realidad de continuo movimiento cíclico de la naturaleza y de su cultura.

a. ¿En qué parte del monte podes observar ciclos o espirales?

b. ¿Qué elementos del cielo Qom podes decir que forman ciclos?

Actividad 3: Verificar las respuestas de cada grupo. Puesta en común de las respuestas en el grupo grande.

Actividad 4: Realización de un collage. A partir de lo leído y de lo conversado entre todos, se les pide a los estudiantes que representen mediante un dibujo, collage, frases, etc. ¿Cómo es la idea de tiempo para la cultura Qom? Siendo la respuesta a esta pregunta de creación y construcción grupal.

Actividad 5: Verificar las respuestas de cada grupo. Puesta en común de las respuestas en el grupo grande.

Actividad 6: Relación entre el reloj y el mapa de la cosmografía Qom. Dados estos dos dibujos pertenecientes a la cultura Qom, obsérvalos y luego responde.

${ }^{2}$ La divulgación de las imágenes tiene el consentimiento de los participantes. 


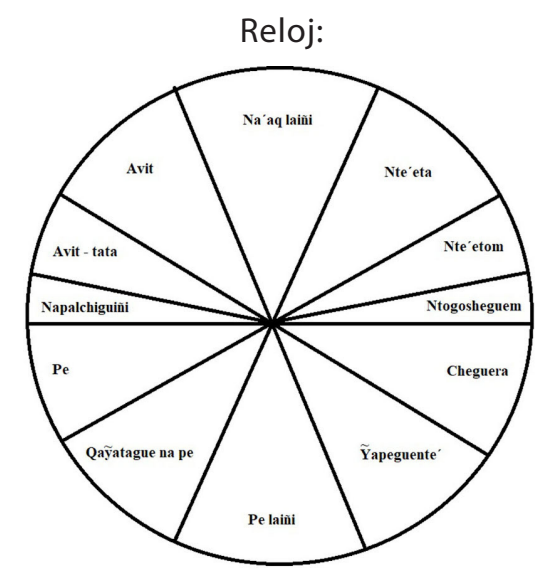

Mapa de cosmografía:

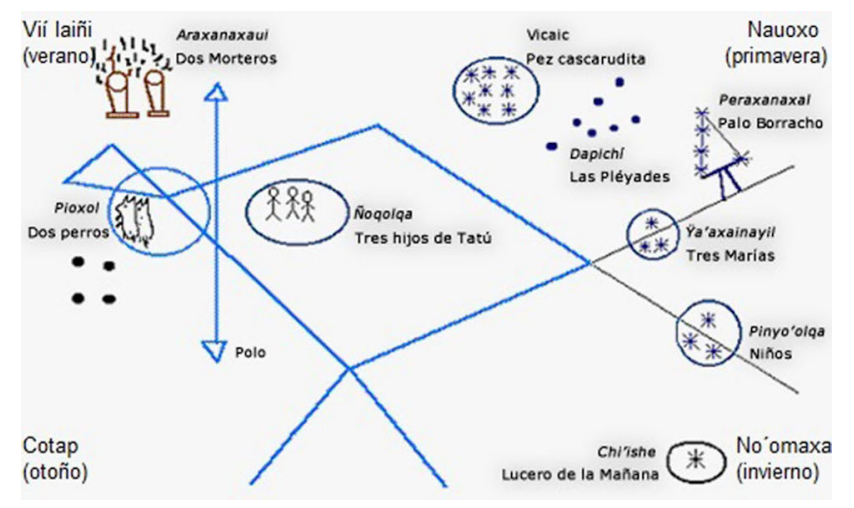

1. Grupo ubica hechos o fenómenos en ambos esquemas mediante la siguiente tabla:

\begin{tabular}{|l|l|l|}
\hline Hecho o fenómeno & Reloj & Mapa de cosmografía \\
\hline & & \\
\hline
\end{tabular}




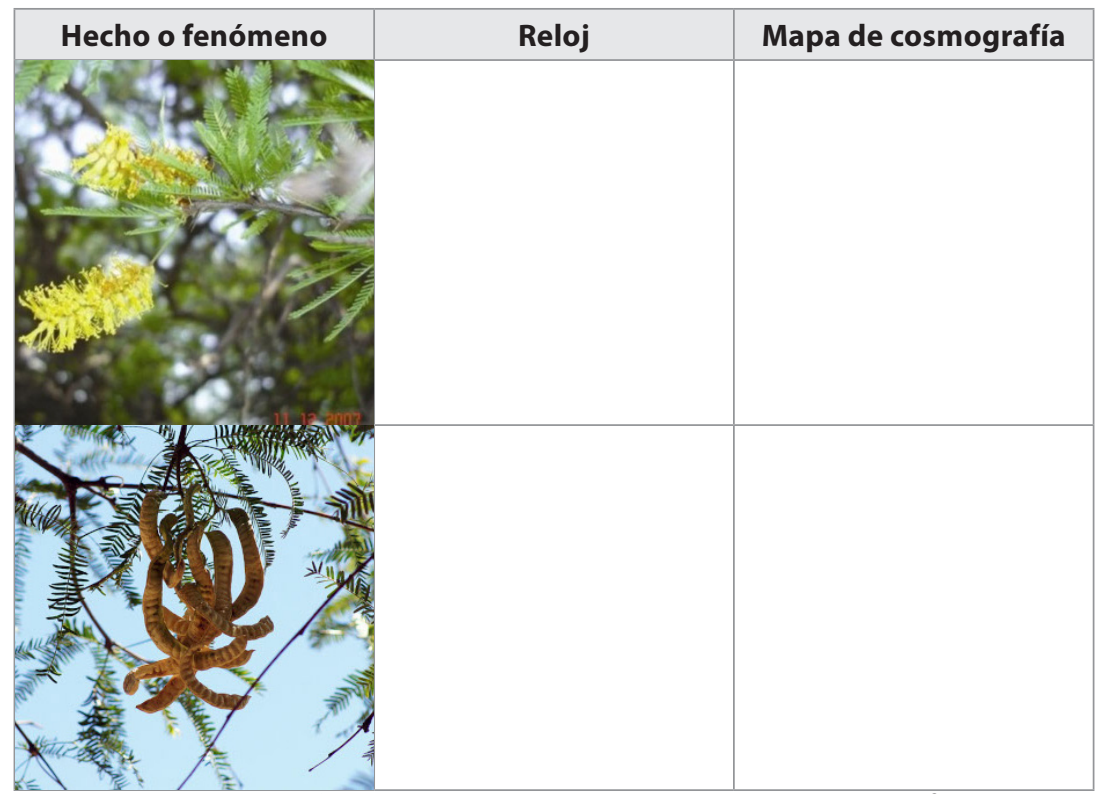

Fuentes: las tres primeras fotografías fueron tomadas durante la investigación ${ }^{3}$. Las dos últimas fueron extraídas de Reserva Natural Educativa Montecito de Lovera (2020).

2. En grupo discutan si las siguientes afirmaciones son verdaderas o falsas teniendo en cuenta: ¿Cómo las modificarían? ¿Qué le agregarían?

a. El primer dibujo marca el paso del tiempo en un día, mientras que el segundo en un año;

b. Los ancianos dicen que para entender el primer dibujo hay que mirar el movimiento del Sol y la Luna;

c. En el segundo dibujo el tiempo se empieza a contar cuando se lo ve a Chi'ishe, el planeta Venus, a la mañana. Es decir, cuando el primer dibujo indica Cheguera;

d. En el segundo esquema se puede observar al ñandú (mañic) girando en círculos en el cielo nocturno y nunca desaparece, siempre está;

e. El Sol se encuentra en su punto más alto del cielo cuando el primer dibujo marca Na'aq laiñi;

f. En verano es tiempo de recolectar algarrobo y se observa a Araxanaxaui y eso aparece en el mapa de cosmografía pero no en el reloj.

Actividad 7: Verificar las respuestas de cada grupo. Puesta en común delas respuestas en el grupo grande.

\section{Resultados}

Las producciones obtenidas en la propuesta mostraron la emergencia de elementos de la cultura Qom por lo tanto podemos afirmar que promovió las expresiones de los jóvenes. Mediante la actividad se obtuvieron como resultado 10 escritos que mostraron que la mayoría de los participantes conocía el reloj Qom propuesto y los nombres de sus intervalos temporales. Sin embargo, existen diferentes versiones de este reloj que se materializaron en las producciones de los estudiantes, ya que algunos agregaron nuevos períodos temporales o quitaron los que se encontraban en el reloj propuesto (Figura 3). 
Figura 3 - Las imágenes muestran dos versiones diferentes del reloj Qom producidos por los estudiantes

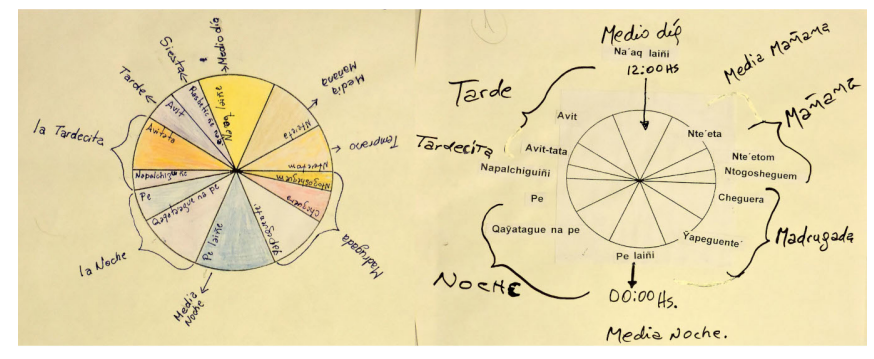

Fuente: selección de imágenes de los collages realizados por los estudiantes durante la investigación.

Es importante destacar que en los collages realizados por los estudiantes existen otros marcadores temporales tales como el canto de aves específicas (Figura 4).

Figura 4 - La imagen muestra figuras de aves indicadoras de períodos temporales

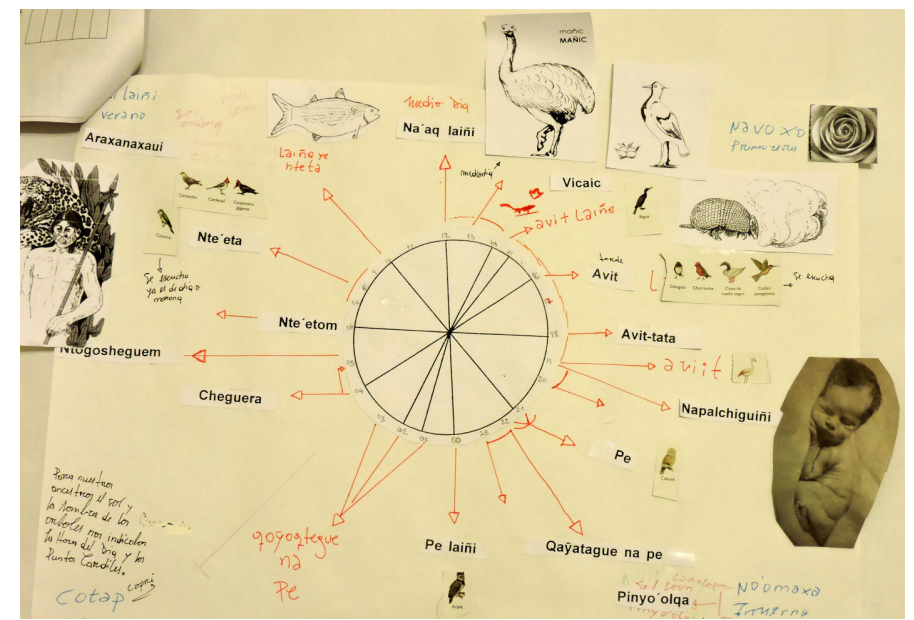

Fuente: selección de un collage realizado por los estudiantes durante la investigación.

Según Arenas y Porini (2009) el canto de las aves aporta referencias temporales, que cobra importancia en días nublados o durante las noches. El canto de palalo'Go (Xolmis irupero) anuncia el comienzo del día y su canto se escucha hacia las dos o tres de la madrugada. Por otra parte, el pelícano (ta'ha:q, Chauna torquata) canta sucesivamente de dos a cuatro veces, a cuyo término está próximo el amanecer. Cuando ya es de día canta el 'pitoGot (Pitangus sulphuratus) y el chingolo (pael'che, Zonotrichia capensis) quien también anuncia la llegada de la noche. Alrededor de las ocho de la mañana cantan las charatas (Ortalis canicollis) quienes evocan que el Sol ya está alto en el horizonte. Las catas (ki'lik, Myiopsitta monachus) cantan al mediodía, dando aviso que son las doce. Por otra parte, la hora del crepúsculo se hace evidente cuando los loros (e'le, Amazona aestiva) retornan a sus nidos. El canto de la brasita de fuego (a'hewa la'lo, Pyrocephalus rubinus) da cuenta de que se hizo noche. Se atribuye a la perdiz ('sodache, Crypturellus tataupa) la cualidad de cantar a la medianoche. Cuando es pasadas de la media noche canta la lechuza (kidi'kik, Asio clamator, Bubo virginianus). Cabe aclarar que el recurrir a los cantos de las aves para definir momentos del día y la noche da a entender una idea de ritmo en la temporalidad tal como lo afirma Carbonell Camós (2004).

Es necesario destacar que los diferentes collages realizados por los estudiantes para responder la pregunta ¿cómo es la idea de tiempo para la cultura Qom? A primera instancia, parecen dar cuenta de una idea cíclica del tiempo, ya que para armar los collages los 
estudiantes eligieron figuras relacionadas con posibles formas espiraladas observables en la naturaleza (Figura 5). Asimismo, consideramos que es necesario desarrollar futuras investigaciones de forma tal de explorar más para saber si es realmente la interpretación de ello.

Figura 5 - Collage realizado por los estudiantes

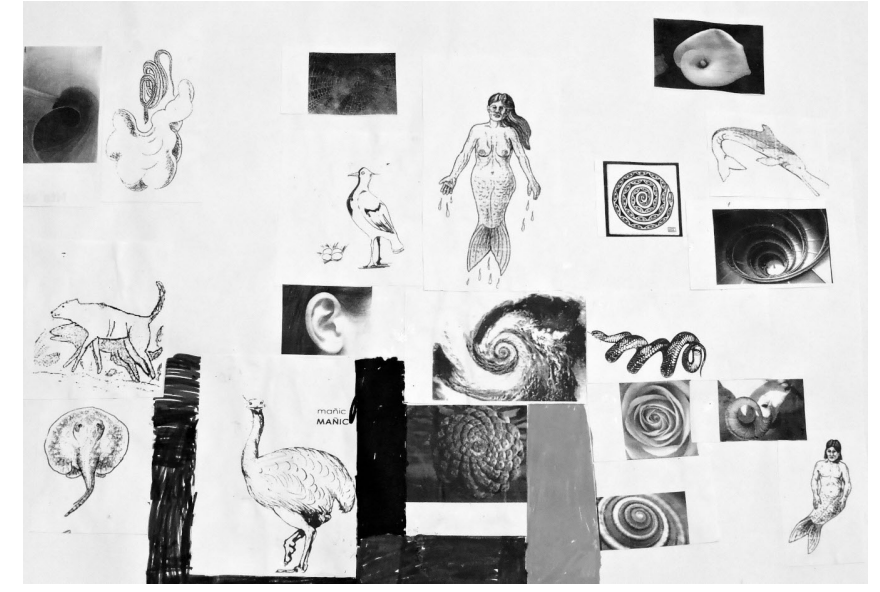

Nota: La imagen muestra un collage realizado por los estudiantes para responder la pregunta ¿cómo es la idea de tiempo para la cultura Qom? A primera instancia, se exhiben formas espiraladas en la naturaliza y algunas figuras de sus deidades culturales.

Fuente: selección de un collage realizado por los estudiantes durante la investigación.

El modo en el que los Qom observan el movimiento aparente del Sol en el cielo es compatible con la concepción astronómica conocida como esfera celeste, ya que su aparición en el horizonte y movimiento son indicadores temporales para la comunidad (SÁNCHEZ, 2010). En algunos collages realizados por los estudiantes se puede observar una idea de Tierra como una gran esfera dividida por dos hemisferios: el inferior es sólido formado por rocas y tierra. Es el hemisferio donde viven las personas, mientras que el superior es paralelo al primero, está hecho de aire y lo llaman cielo. A su vez, puede decirse que el aire cubre el suelo y toca el borde redondo de la Tierra. Así el Sol, la Luna y las estrellas se conciben en el interior de la bola, pues fuera de ella se encuentra el espacio vacío (NUSSBAUM, 1989). En esta noción se manifiesta la idea de que el Sol viaja por el cielo deslizándose bajo la Tierra para salir nuevamente la cual se plasma en los dibujos realizados por los estudiantes se observa al reloj Qom dividido en la semiesfera superior llamada día y la inferior (Figura 6).

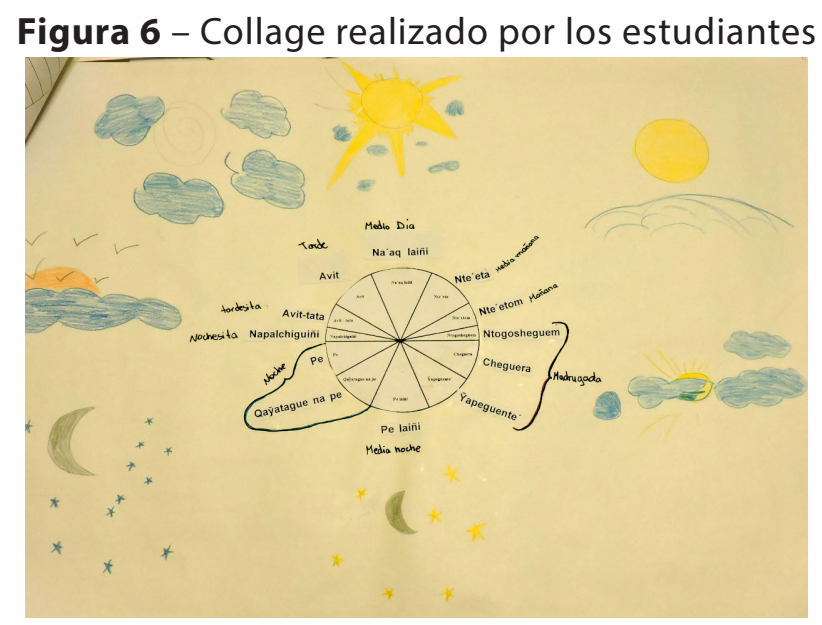

Nota: Se observa un collage realizado por los estudiantes donde se muestra al reloj Qom dividido en dos hemisferios, el superior representa al día y el inferior a la noche.

Fuente: collage realizado por los estudiantes durante la investigación. 
Cabe aclarar que de las respuestas de los estudiantes se deprende que si bien para dar cuenta del tiempo diurno los Qom observan el movimiento aparente del Sol, para la noche se guían por la claridad u oscuridad atmosférica.

Teniendo como referencia los marcos teóricos de la Didáctica de la DCN y siguiendo a Vosniadou (2002), la noción de la Tierra como esfera es aceptada en la mayoría de las culturas. Sin embargo, esta última autora afirma que existen diferencias significativas con las cosmologías indígenas, es por eso que los niños pertenecientes a estas culturas presentan notables diferencias con los modelos científicos occidentales. Los modelos de culturas indígenas muchas veces están teñidos de mitologías, las cuales son más accesibles a los niños que sus equivalentes precopernicanos de la ciencia occidental (VOSNIADOU, 2002).

Esta misma autora manifiesta la posibilidad de que las cosmovisiones indígenas a las cuales pertenezcan los niños intervinientes tengan grandes influencias en la construcción de modelos correspondientes a los conceptos astronómicos, siendo la cultura de pertenencia quien permée la reorganización de los modelos científicos adquiridos en la escolarización. De esta manera, cuando en estas instituciones se enseñe que la Tierra es redonda los niños intenten acomodarlo a su experiencia cultural. Con lo cual los modelos de Tierra que cimentan los niños de diferentes culturas están regidos por sus cosmovisiones sobre la misma. De esta manera, los niños de culturas diferentes fabricarán modelos distintos de la Tierra, reflejando sus experiencias culturales. En el caso particular de este trabajo, es necesario aclarar que falta explorar más para saber si esa es realmente la interpretación de los estudiantes.

\section{Conclusiones}

Las indagaciones realizadas sobre las concepciones de tiempo Qom presentes en aulas de escuelas secundarias del Gran Chaco argentino resultaron relevantes para los objetivos propuestos. El proceso en sí mismo resultó productivo: se generaron actividades a partir de hipótesis previamente planteadas a través de fuentes bibliográficas y previos trabajos de campo. Las regularidades en las producciones de los estudiantes develaron algunas de nuestras interrogantes. Mediante esta primera etapa exploratoria de investigación de doctorado se dilucidó que para los Qom la observación de los cambios de la naturaleza son formas de establecer intervalos de tiempo, los cuales se observan a través de las modificaciones producidas en las plantas, los animales y el canto de las aves.

Estos fenómenos establecen estrechas relaciones con las estaciones del año del calendario occidental. Asimismo, el Sol es un indicador diurno del paso del tiempo porque establece los intervalos de luz disponibles para las tareas diarias de la comunidad. Un marcador temporal de gran importancia es lo que los astrónomos llaman mediodía solar, este fenómeno ocurre todos los días cuando el Sol está en su punto más alto en el cielo y las sombras producidas por su luz tienen la menor longitud posible. El mediodía solar muchas veces no coincide con la hora que marca el reloj porque esta es una hora civil que rige en un territorio, mientras que la hora de Sol es local y depende de la longitud cartográfica del observador.

Por otra parte, los movimientos de algunos grupos de estrellas particulares son indicadores del paso del tiempo en el cielo nocturno relacionados con el ciclo anual. Algunos grupos de estrellas se asocian con una serie de relatos que subsumen dentro de sí la constitución del orden espacial para los Qom, que consideran la Tierra plana conformada por diferentes estratos, con seres que la habitan y se transforman en humanos a no humanos 
cuando transitan de un plano al otro. Siguiendo a Chadwick y Bonan (2018), los estratos que conforman al mundo Qom son paralelos entre sí y a su vez se estratifican, los principales son el cielo (Piguem), le sigue hacia abajo la tierra (Aluha) y finalmente, el agua (Etaxat). Por otra parte, la manera en la que los Qom interpretan la forma de la Tierra está relacionada con lo que Vosniadou (2002) sostiene como la Tierra como esfera hueca, es decir, una Tierra esférica suspendida en el cielo como planeta que tiene adentro un piso plano donde viven las personas.

El modelo mental de Tierra para los Qom se relaciona con una serie de relatos y seres de poder, dicha relación es pensada de modo que se trata de un producto cognoscitivo en el interior de esos relatos, es un conocimiento del mundo astronómico pero al interior de una cosmovisión preexistente a los individuos de la cultura Qom, es decir que no es independiente de esta. Por lo tanto, podemos decir que los relatos de la cultura Qom son más accesibles que sus equivalentes precopernicanos de la ciencia occidental. Asimismo, cabe afirmar que la cosmovisión Qom a la que pertenecen los participantes tienen grandes influencias en la construcción de modelos correspondientes a conceptos astronómicos, siendo su cultura quien permea la reorganización de los modelos científicos adquiridos en la escolarización. De esta manera, cuando en estas instituciones se enseñe que la Tierra es redonda los estudiantes probablemente intentaran acomodarlo a su experiencia cultural. Con lo cual los modelos de Tierra que cimentan los estudiantes Qom están regidos por sus cosmovisiones sobre la misma.

Asimismo, los collages exhiben en una primera instancia imágenes de representaciones cíclicas del tiempo. Sin embargo, debemos destacar la necesidad de generar futuras investigaciones para profundizar más en las representaciones temporales de los estudiantes. Es por eso, que el proyecto de doctorado propone una segunda fase de investigación de estilo etnográfico de forma tal de poder precisar cómo son estas representaciones cíclicas, si son circulares, espirales, fractales o alguna de sus posibles variantes.

La intervención en las instituciones educativas de nivel medio posibilitó explorar el dispositivo didáctico diseñado y, con ello, la potencia de su elaboración a partir de la consulta de las fuentes teóricas y de la aplicación de los marcos teóricos de la Didáctica de las Ciencias Naturales.

La elaboración del dispositivo conlleva la elaboración de materiales didácticos que permiten socializar la experiencias en otros contextos.

\section{Referencias}

ADÚRIZ-BRAVO, A.; GODOY, E.; IGLESIAS, M.; BONAN, L.; GONZÁLEZ GALLI, L. Las imágenes de ciencia y de científico en una propuesta de educación inclusiva para todos y todas. In: MORENO, M. B.; AÑAÑOS BEDRIÑANA, F. T. Educación social: formación, realidad y retos. Granada: GEU, 2006. p. 427-435.

ARENAS, P.; PORINI, G. Las aves en la vida de los Tobas del oeste de la provincia de Formosa (Argentina). Asunción: Tiempo de Historia, 2009.

ARGENTINA. Ministerio de Educación, Cultura, Ciencia y Tecnología. Currículum para la educación primaria del Chaco. [Buenos Aires]: Ministerio de Educación, Cultura, Ciencia y Tecnologia, 2012. Recuperado el 21 sep. 2020 de: https://cutt.ly/tfLPt9h.

BONAN, L. Cómo se define un problema de investigación en didáctica de las ciencias naturales. In: FIORITI, G.; MOGLIA, P. La formación docente y la investigación en didácticas específicas. San Martín: UNSAM, 2005. p. 125-130. 
BONAN, L. La formación docente y la creación de materiales didácticos para la educación científica intercultural. In: QUINTANILLA GATICA, M. (comp.). Multiculturalidad y diversidad en la enseñanza de las ciencias: hacia una educación inclusiva y liberadora. Santiago de Chile: Bellaterra, 2017. p. 50-70.

CARBONELL CAMÓS, E. Debates acerca de la antropología del tiempo. Barcelona: Universidad de Barcelona, 2004.

CENSABELLA, M. Las lenguas indígenas de la Argentina: una mirada actual. Buenos Aires: Eudeba, 2005.

CHADWICK, G.; BONAN, L. Educación científica intercultural: tendiendo puentes conceptuales sobre las Pléyades en el Gran Chaco. Tecné, Episteme y Didaxis: TED, Bogotá, n 43, p. 17-29, 2018. Recuperado el 21 sep. 2020 de: https://cutt.ly/HfLPLIt.

CUBERO, R. Concepciones alternativas, preconceptos, errores conceptuales... ¿distinta terminología y un mismo significado? Investigación en la Escuela, Sevilla, n. 23, p. 33-43, 1994. Recuperado el 21 sep. 2020 de: https://revistascientificas.us.es/index.php/IE/article/view/8468.

CULLEN, C. Reflexiones desde nuestra América. Buenos Aires: Editorial Las Cuarenta, 2017.

DRIVER, R.; GUESNE, E.; TIBERGHIEN, A. Las ideas de los niños y el aprendizaje de las ciencias. In: DRIVER, R.; GUESNE, E.; TIBERGHIEN, A. (coord.). Ideas científicas en la infancia y la adolescencia. Madrid: Morata, 1989. p. 19-30.

ELÍAS, N. Sobre el tiempo. 3. ed. México: Fondo de Cultura Económica, 2010.

FREIRE, P. ¿Extensión o comunicación?: la concientización en el medio rural. 2. ed. Ciudad de México: Siglo XXI, 1973.

FREIRE, P. Pedagogía del oprimido. 2. ed. Montevideo: Tierra Nueva, 1970.

FREIRE, P. Pedagogy of indignation. 2. ed. Boulder: Paradigm, 2004.

GRAMSCl, A. Notas sobre Maquiavelo, sobre la política y sobre el estado moderno. Ciudad de México: Juan Pablos, 1975.

HECHT, A. C.; SCHMIDT, M. A. (comp.). Maestros de la educación intercultural bilingüe: regulaciones, experiencias y desafíos. Buenos Aires: Novedades Educativas, 2016.

HIRSCH, S. Pensando la educación cultural bilingüe en contextos pluriétnicos y plurilingüísticos. In: HIRSCH, S.; SERRUDO, A. (comp.). La educación intercultural bilingüe en Argentina: identidades, lenguas y protagonistas. Buenos Aires: Novedades Educativas, 2010. p. 121-148.

HIRSCH, S.; SERRUDO, A. (comp.). La educación intercultural bilingüe en Argentina: identidades, lenguas y protagonistas. Buenos Aires: Novedades Educativas, 2010.

LEACH, E. Replanteamiento de la antropología. Barcelona: Seix Barral, 1971.

NUSSBAUM, J. La tierra como cuerpo cósmico. In: DRIVER, R.; GUESNE, E.; TIBERGHIEN, A. (coord.). Ideas científicas en la infancia y la adolescencia. Madrid: Morata, 1989. p. 259-290.

QUIJANO, A. Colonialidad del poder, eurocentrismo y América Latina. In: LANDER, E. (comp.). La colonialidad del saber: eurocentrismo y ciencias sociales: perspectivas latinoamericanas. Buenos Aires: CLACSO, 2003. p. 201-246.

RESERVA NATURAL EDUCATIVA MONTECITO DE LOVERA. [2020]. Recuperado el 22 sep. 2019 de: https://cerrito.gob.ar/reservalovera/? $p=728$.

SÁNCHEZ, O. Rasgos culturales de los Tobas. Resistencia, Argentina: Librería de la Paz, c2010. 
SANTOS, B. S. Another production is possible: beyond the capitalist canon. London: Verso, 2006.

SARASOLA, C. Nuestros paisanos los indios. Buenos Aires: Del Nuevo Extremo, 2013.

SIRVENT, M. T.; RIGAL, L. Investigación acción participativa: un desafío para nuestros tiempos para la construcción de una sociedad democrática. Buenos Aires: Páramos Andinos, 2012.

THISTED, S. Culturas magisteriales y educación intercultural en argentina: construcción histórica de posiciones docentes ante las diferencias y las desigualdades. In: SEMINARIO INTERNACIONAL DE LA RED ESTRADO, 11., 2016, México D.F. Trabajos presentados [...]. Recuperado el 20 mar. 2020 de: http://redeestrado.org/xi_seminario/pdfs/eixo8/306.pdf.

TOLA, F. Yo no estoy solo en mi cuerpo. Buenos Aires: Biblos, 2012.

TOLA, F. El teatro chaqueño de las crueldades: memorias Qom de la violencia y el poder. Buenos Aires: Asociación Civil Rumbo Sur, 2016.

VOSNIADOU, S. Propiedades universales y culturo-específicas de los modelos mentales de los niños acerca de la Tierra. In: HIRSCHFELD, L.; GELMAN, S. (comp.). Cartografía de la mente: la especificidad de dominio en la cognición y en la cultura. Barcelona: Gedisa, 2002. p. 221-243.

WALSH, C. Interculturalidad, conocimientos y decolonialidad: perspectivas y convergencias. Signo y Pensamiento, Bogotá, v 24, n 46, p. 39-50, 2005.

WALSH, C. Interculturalidad crítica y educación intercultural. In: VIAÑA UZIEDA, J.; TAPIA MELLA, L.; WALSH, C. E. Construyendo interculturalidad crítica. La Paz: Convenio Andrés Bello: Instituto Interamericano de Integración, c2010. p. 75-96.

ZIRADICH, M. Pareja vulnerable, si la hay: docente originario y docente no originario. In: HIRSCH, S.; SERRUDO, A. (comp.). La educación intercultural bilingüe en Argentina: identidades, lenguas y protagonistas. Buenos Aires: Novedades Educativas, 2010. p. 223-254. 